\title{
Biological nitrogen fixation in the oxygen-minimum region of the eastern tropical North Pacific ocean
}

\author{
Amal Jayakumar ${ }^{1}$, Bonnie X Chang ${ }^{2,3}$, Brittany Widner ${ }^{4}$, Peter Bernhardt ${ }^{4}$, \\ Margaret R Mulholland ${ }^{4}$ and Bess B Ward ${ }^{1}$

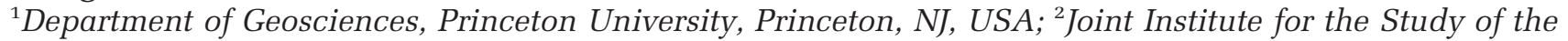 \\ Atmosphere and Ocean, University of Washington, Seattle, WA, USA; ${ }^{3}$ NOAA/Pacific Marine Environmental \\ Laboratory, Seattle, WA, USA and ${ }^{4}$ Department of Ocean, Earth and Atmospheric Sciences, Old Dominion \\ University, Norfolk, VA, USA
}

\begin{abstract}
Biological nitrogen fixation (BNF) was investigated above and within the oxygen-depleted waters of the oxygen-minimum zone of the Eastern Tropical North Pacific Ocean. BNF rates were estimated using an isotope tracer method that overcame the uncertainty of the conventional bubble method by directly measuring the tracer enrichment during the incubations. Highest rates of BNF $\left(\sim 4 \mathrm{~nm}\right.$ day $\left.^{-1}\right)$ occurred in coastal surface waters and lowest detectable rates $\left(\sim 0.2 \mathrm{~nm}^{\left.-1 a y^{-1}\right)}\right.$ were found in the anoxic region of offshore stations. BNF was not detectable in most samples from oxygen-depleted waters. The composition of the $\mathrm{N}_{2}$-fixing assemblage was investigated by sequencing of nifH genes. The diazotrophic assemblage in surface waters contained mainly Proteobacterial sequences (Cluster I nifH), while both Proteobacterial sequences and sequences with high identities to those of anaerobic microbes characterized as Clusters III and IV type nifH sequences were found in the anoxic waters. Our results indicate modest input of $\mathrm{N}$ through BNF in oxygen-depleted zones mainly due to the activity of proteobacterial diazotrophs.
\end{abstract}

The ISME Journal (2017) 11, 2356-2367; doi:10.1038/ismej.2017.97; published online 25 July 2017

\section{Introduction}

The balance between nitrogen $(\mathrm{N})$ losses via denitrification (including anammox) and inputs via biological dinitrogen $\left(\mathrm{N}_{2}\right)$ fixation $(\mathrm{BNF})$, along with physical fluxes, determines the fixed $\mathrm{N}$ inventory of the ocean. BNF has traditionally been associated with the euphotic zone of oligotrophic regions while denitrification occurs in the absence of oxygen in both the water column and sediments.

Oxygen-minimum zones (OMZs), where dissolved oxygen is undersaturated relative to surrounding waters, occur across all ocean basins as the result of respiration of organic matter. Only in a few regions, which we refer to as oxygen-depleted zones (ODZs), are oxygen concentrations low enough to induce anaerobic metabolisms. It has long been recognized that ODZs are major sites for net $\mathrm{N}$ loss from the ocean. It has also been argued that, owing to the relative decrease in $\mathrm{N}$ availability associated with these $\mathrm{N}$ losses, the low oxygen concentrations (Mulholland and Capone, 2009; Großkopf and Laroche, 2012), and the relatively high available iron concentrations in ODZs, $\mathrm{N}_{2}$ fixation should also

Correspondence: A Jayakumar, Department of Geosciences, Princeton University, Princeton, NJ 08544, USA.

E-mail: ajayakum@princeton.edu

Received 3 November 2016; revised 31 March 2017; accepted 12 May 2017; published online 25 July 2017 be favored in ODZs (Deutsch et al., 2007; Mulholland and Capone, 2009). Efforts to test this idea have focused on the Eastern Tropical South Pacific (ETSP) ODZ, one of the three major oceanic ODZs, which together account for up to one-third of the global marine fixed $\mathrm{N}$ loss (Devol, 2008). Recent expeditions have reported BNF in both surface and deeper (anoxic) waters of this region (Fernandez et al., 2011; Bonnet et al., 2013; Dekaezemacker et al., 2013; Loescher et al., 2014) and have described diverse assemblages of diazotrophic microbes on the basis of their nifH genes (Loescher et al., 2014; Turk-Kubo et al., 2014). These studies reported anoxic BNF rates of up to $25 \mathrm{~nm} \mathrm{day}^{-1}$ (Loescher et al., 2014), which could contribute significantly to overall global BNF rates, and detected novel groups of previously unknown diazotrophic microbes, distinct from the well-known cyanobacterial $\mathrm{N}_{2}$ fixers.

Global marine $\mathrm{N}$ budgets generally assume that biological $\mathrm{N}$ loss and input processes are roughly balanced, but such budgets contain large uncertainties, beginning with the methods used to make direct rate measurements of the processes and the paucity of such data. Recent improvements in the methods used to measure the rates of both $\mathrm{N}$ loss and $\mathrm{N}_{2}$ fixation have greatly expanded the global data sets for these two major pathways in the $\mathrm{N}$ cycle. The exetainer method for measuring denitrification and anammox (Thamdrup and Dalsgaard, 2002) facilitated the direct measurement of $\mathrm{N}$ losses from the 
ocean while the bubble method for $\mathrm{N}_{2}$ fixation (Montoya et al., 1996) did the same for the measurement of BNF rates in many regions of the world ocean. However, the conventional bubble method can underestimate BNF rates by a variable amount (Mohr et al., 2010; Großkopf et al., 2012). This uncertainty complicates the extrapolation of direct rate measurements of $\mathrm{N}_{2}$ fixation for comparison with geochemical estimates of this important global $\mathrm{N}$ budget term.

The goal of the present study was to investigate the distribution and magnitude of BNF in the Eastern Tropical North Pacific Ocean (ETNP), where much less is known about $\mathrm{N}$ losses and $\mathrm{N}_{2}$ fixation than in the ETSP. In and around the ETNP ODZ, we quantified BNF using an improved method that overcomes the uncertainty of the bubble method and avoids perturbation of natural water samples with equilibrated enriched seawater. We also examined the phylogenetic composition of the $\mathrm{N}_{2}$-fixing assemblage by sequencing cloned nifH genes from both surface and anoxic waters.

\section{Materials and methods}

Water samples were collected from multiple casts at each of the two stations, nearshore Station BB1 and offshore Station BB2, in the ETNP (Figure 1) during March and April of 2012 aboard the $R / V$ Thomas G. Thompson. Casts 108, 110, 111, 120 and 124 were all at Station BB1 and Casts 138, 146 and 151 were all at BB2. Additional samples were collected at another nearshore station (Cast 103), on a transect perpendicular to the coast (Casts 134 and 163) and along a meridional transect along $110^{\circ} \mathrm{W}$ (Casts 168, 173 and 179) (Figure 1). High-resolution water-column nitrate, nitrite and oxygen concentrations at Stations BB1 and BB2 were reported previously (Peng et al., 2015).

Water for BNF incubations was collected in triplicate from Niskin bottles (General Oceanics, Miami, FL, USA) mounted on a CTD rosette (SeaBird Electronics, Bellevue, WA, USA). Euphotic zone samples were collected from predawn casts and incubated in $2.5 \mathrm{l}$ transparent polycarbonate bottles fitted with septa caps. Incubation bottles were placed in flow-through incubators on deck where temperature was maintained with flowing surface seawater and in situ light levels, estimated from the CTD PAR data, were simulated using neutral density screens.

ODZ samples were incubated in transparent acidwashed $(10 \% \mathrm{HCl})$, helium-purged, evacuated, 2-mil-thick polyvinyl fluoride gas-tight $5 \mathrm{l}$ Tedlar bags (Cole Parmer, Vernon Hills, IL, USA) with dual entry points: one a nickel-plated brass hose barb and the other a septum (Cole Parmer, Vernon Hills, IL, USA, EW-01409-92). Samples were transferred into the bags directly from the Niskin bottle using inert tubing attached to the hose barb, and remaining helium was removed from the bags via syringe

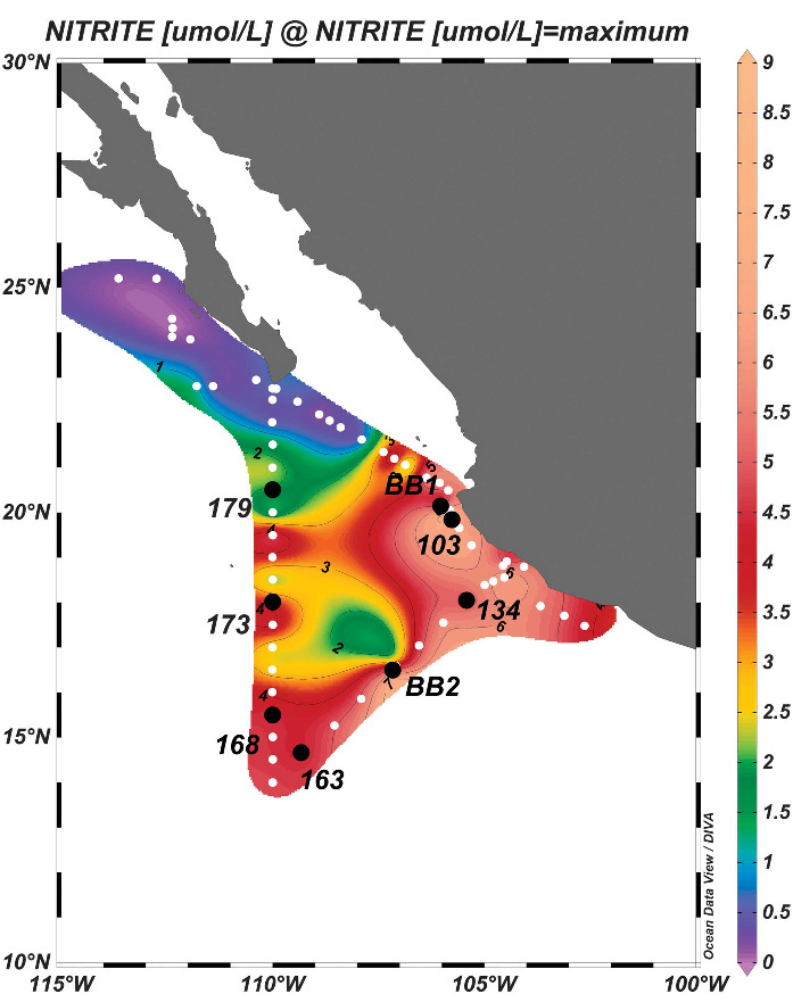

Figure 1 Map of station locations. Station BB1 includes Casts 108, 110, 111, 120 and 124. Station BB2 includes Casts 138, 146 and 151. White dots indicate stations on the cruise track that were used to derive the background contours of maximum $\mathrm{NO}_{2}^{-}$ concentration, which defines the oxygen-depleted water in the OMZ region.

attached to the septum during filling. Atmospheric $\mathrm{O}_{2}$ contamination during water collection was minimized by continually flushing the head-space of the Niskin bottles with $\mathrm{He}$ gas. ODZ samples were incubated in a cold van $\left(12^{\circ} \mathrm{C}\right)$ in the dark (in situ temperature $12-13^{\circ} \mathrm{C}$ ).

${ }^{15} \mathrm{~N}_{2}$ tracer (99\%, Cambridge Isotope Labs, Tewksbury, MA, USA) was injected into bottles and bags through the septa to a target concentration of $\sim 10 \%$ ambient $\mathrm{N}_{2}$. The duration of all incubations was $\sim 24 \mathrm{~h}$ in order to capture the full diel light cycle in euphotic waters, where many diazotrophs exhibit diurnal cycles of $\mathrm{N}_{2}$ fixation (Zehr et al., 2007). Incubations were terminated by filtering the entire contents of the incubations onto precombusted $\left(450^{\circ} \mathrm{C}\right.$ for $2 \mathrm{~h}$ ) GF/F filters (Whatman, UK) (nominal pore size $0.7 \mu \mathrm{m}$ ). Filters were stored at $-20^{\circ} \mathrm{C}$, then dried and pelletized in tin discs and analyzed for isotopic enrichment on a Europa Geo 20/20 isotope ratio mass spectrometer (Little Chalfont, Buckinghamshire, UK) equipped with an automated nitrogen and carbon analyzer. To characterize and correct for the effect of a nonlinear detector response to varying sample size, known standards of different sample masses were run, bracketing the expected sample mass (Mcilvin and Casciotti, 2010). Samples to determine the initial isotopic composition of particulate organic matter in incubations were collected in triplicate on GF/F filters. 
Rates of BNF were calculated using Equation (1):

$\mathrm{N}_{2}$ fixation rate $=\frac{\left(A_{\mathrm{PN}}^{\text {final }}-A_{\mathrm{PN}}^{t=0}\right)}{\left(A_{\mathrm{N}_{2}}-A_{\mathrm{PN}}^{t=0}\right)} \times \frac{[\mathrm{PN}]}{\Delta t}$

where $A=$ atom $\%{ }^{15} \mathrm{~N}$ measured in the particulate organic $\mathrm{N}(\mathrm{PN})$ at the end (final) or beginning $(t=0)$ of the incubation or in the dissolved $\mathrm{N}_{2}$ pool $\left(\mathrm{N}_{2}\right)$ (Montoya et al., 1996; Mulholland et al., 2006).

The method detection limit was calculated using the method of Santoro et al. (2013), except that we used $3 \times$, instead of $2 \times$, of the instrument s.d. to compute the limit. That is, the s.d. of the atom percent from seven standards of $12 \mu \mathrm{g} \mathrm{N}$ each $(0.0025 \%)$ was multiplied by three and added to the initial atom percent measurement for each sample. This was the minimum detectable final particulate atom percent enrichment (Analytical Detection Limit Guidance \& Laboratory Guide for Determining Method Detection Limits, Wisconsin Department of Natural Resources Laboratory Certification Program, April 1996, PUBL-TS-056-96). This value was then forced through the calculation for each measurement to account for variability in particulate nitrogen concentrations with depth and incubation times, resulting in an independent detection limit for each measurement. The mean detection limit was $1.0 \mathrm{nmol} \mathrm{Nl}^{-1}$ day $^{-1}$. The average detection limit for oxic incubations was substantially higher than for anoxic incubations (1.4 and $0.5 \mathrm{nmol} \mathrm{Nl}^{-1}$ day $^{-1}$, respectively), due to large differences in particulate nitrogen concentrations between samples. Only rates above the detection limit (ADL) for that specific measurement are considered significant.

In order to estimate the change in atom $\%{ }^{15} \mathrm{~N}$ of the substrate $\mathrm{N}_{2}$ pool over time due to gradual equilibration of the ${ }^{15} \mathrm{~N}_{2}$ gas bubble, parallel incubations were carried out, in duplicate, using filtered seawater held at four different temperatures in a range approximating in situ temperatures $\left(5-18.5^{\circ} \mathrm{C}\right)$. The incubations were subsampled at $2 \mathrm{~h}$ intervals for the first $10 \mathrm{~h}$ and 4-6 h intervals thereafter (up to $24 \mathrm{~h}$ ) into He-purged $12 \mathrm{ml}$ Exetainers (Labco, Lampeter, UK), which were immediately poisoned with $0.05 \mathrm{ml} 7 \mathrm{M} \mathrm{ZnCl}$. Exetainers were analyzed for atom $\%{ }^{15} \mathrm{~N}_{2}$ on a Europa 20/20 isotope ratio mass spectrometer. Separate polynomials for each temperature were fit to the resultant time-dependent equilibration curves. Each polynomial was integrated from 0 to $24 \mathrm{~h}$ and the result was divided by 24 to estimate the average atom $\%{ }^{15} \mathrm{~N}_{2}$ in sample incubations over the course of a 24 $\mathrm{h}$ incubation. Average atom $\%{ }^{15} \mathrm{~N}_{2}$ ranged from $3.9 \%$ at $5{ }^{\circ} \mathrm{C}$ to $5.5 \%$ at $18.5^{\circ} \mathrm{C}$ (see Supplementary Figure).

DNA/RNA sequence analysis

Particulate material from five depths was collected for nifH sequence analysis: near surface $(0 \mathrm{~m})$, chlorophyll maximum (18 m), and secondary nitrite maximum (SNM, $90 \mathrm{~m}$ ) at Station BB1 and near surface $(0 \mathrm{~m})$ and SNM $(150 \mathrm{~m})$ at Station BB2. Whole water (4-8 l) from CTD-mounted Niskin bottles was filtered through Sterivex-GP capsule filters (Millipore, Inc., Bedford, MA, USA), using a peristaltic pump, quick frozen in liquid nitrogen and shipped in liquid nitrogen to Princeton University. The samples were stored at $-80^{\circ} \mathrm{C}$ until DNA/RNA was extracted.

DNA and RNA were simultaneously extracted from Sterivex filters using the ALLPrep DNA/RNA Mini Kit (Qiagen Sciences, Germantown, MD, USA). cDNA was synthesized immediately following purification of RNA using a SuperScript III First Strand Synthesis System (Invitrogen, Carlsbad, CA, USA) following the procedure described by the manufacturer, including RT controls. DNA was quantified using the PicoGreen dsDNA Quantification Kit (Invitrogen) according to the manufacturer's specifications. nifH sequences were amplified from environmental DNA and cDNA using the Promega PCR Kit (Promega, Madison, WI, USA), on an MJ100 Thermal Cycler (MJ Research, Watertown, MA, USA). A nested reaction was used, as previously described (Zehr et al., 1998), with slight modification: $25 \mu \mathrm{l}$ PCR reactions were amplified for 30 cycles $\left(1 \mathrm{~min}\right.$ at $98^{\circ} \mathrm{C}, 1 \mathrm{~min}$ at $57^{\circ} \mathrm{C}, 1 \mathrm{~min}$ at $\left.72^{\circ} \mathrm{C}\right)$, first with the outer PCR primers (Zani et al., 2000), followed by amplification with the inner PCR primers (Zehr and McReynolds, 1989). In order to minimize the possibility of amplifying contaminants (Zehr et al., 2003), negative controls (autoclaved and ultraviolet-irradiated water) were run with every PCR experiment, reagents were diluted in freshly autoclaved water, the PCR preparation station was ultraviolet irradiated for $1 \mathrm{~h}$ before each daily use and the number of cycles was limited to 30 for each reaction. The PCR reagents except for the primers were also irradiated. Each reagent was then tested separately for amplification in negative controls.

Amplified fragments were electrophoresed on $1.2 \%$ agarose gels and nifH bands were excised and then cleaned using a QIAquick Nucleotide Removal Kit (Qiagen). Cleaned fragments were inserted into a pCR 2.1-TOPO vector using the One Shot TOP10 Chemically Competent $E$. coli, TOPO TA Cloning Kit (Invitrogen) according to the manufacturer's specifications. This resulted in a total of 10 clone libraries, a DNA and a cDNA library from each depth.

Clones were picked randomly and amplified using M13 Forward (-20) and M13 Reverse primers. The products were sequenced at the Macrogen DNA Analysis Facility using Big Dye terminator chemistry (Applied Biosystems, Carlsbad, CA, USA). Sequences were edited using FinchTV ver. 1.4.0 (Geospiza Inc., Seattle, WA, USA) and checked for identity using BLAST. Consensus nifH sequences (359 bp) were translated to amino acid (aa) sequences (108 aa after trimming the primer region) and aligned using ClustalX (Thompson et al., 1997) along with published nifH sequences from the NCBI database. Neighbor-joining trees were produced from the 
alignment using distance matrix methods (PAUP 4.0, Sinauer Associates, Sunderland, MA, USA). Bootstrap analysis was used to estimate the reliability of phylogenetic reconstruction (1000 iterations). The nifH sequence from Methanosarcina lacustris (AAL02156) was used as an outgroup. The new ETNP nifH sequences have been deposited in GenBank, DNA sequence accession numbers KY967751-KY967929 and cDNA sequence accession numbers KY967930-KY968089.

\section{Results}

Hydrography

An oxygen-deficient zone was present at all the stations sampled. Based on measurements made with the STOX sensor at the same stations on the same cruise (Tiano et al., 2014), the water column $<60 \mathrm{~m}$ at the inshore stations and $<100 \mathrm{~m}$ at the offshore stations to a depth of 700-800 $\mathrm{m}$ can be considered functionally anoxic $\left(\mathrm{O}_{2}\right.$ concentration $\left.<100 \mathrm{~nm}\right)$. Nitrite was detectable in the anoxic layers and the highest $\mathrm{NO}_{2}^{-}$concentration $(7 \mu \mathrm{M})$ occurred at $100 \mathrm{~m}$ at a coastal station (Station BB1, Cast 110; Peng et al., 2015). Highest $\mathrm{NO}_{2}^{-}$and $\mathrm{NO}_{3}^{-}$concentrations were found in the anoxic layers; both were depleted to submicromolar levels in surface waters. The depth distribution of hydrochemistry is shown for depths at which incubations were performed in the coastal region (Stations BB1, 103, 134; Figure 2a) and offshore region (Stations BB2, 163, 168, 173, 179; Figure 2b).

\section{$\mathrm{N}_{2}$-fixation rates}

BNF was ADL in 7 of the 9 surface (2-4 m) samples $(\mathrm{ADL}=$ red symbols in Figures $2 \mathrm{a}$ and $\mathrm{b})$ with a maximum rate of $3.3 \mathrm{~nm} \mathrm{day}^{-1}$. When ADL, BNF in surface waters averaged 2.9 (s.d. $=0.57) \mathrm{nm} \mathrm{day}^{-1}$ at the coastal stations and 0.39 (s.d. $=0.12) \mathrm{nm} \mathrm{day}^{-1}$ at the offshore stations. The highest BNF rates were found at the coastal stations in the upper $20 \mathrm{~m}$ (Figure 2a). The highest recorded rate of $4.3 \mathrm{~nm}^{2} \mathrm{day}^{-1}$ was measured in water samples collected from $20 \mathrm{~m}$ at coastal station 108. BNF was ADL in 5 out of 18 ODZ incubations $\left(\right.$ mean $=0.79$, s.d. $=0.48 \mathrm{~nm} \mathrm{day}^{-1}$ ) and did not differ between offshore and nearshore stations. The maximum rate detected at ODZ depths was $1.7 \mathrm{~nm} \mathrm{day}^{-1}$ at $200 \mathrm{~m}$ at Station 134 , and the other four ADL rates in the ODZ were $<0.6 \mathrm{~nm} \mathrm{day}^{-1}$ (Figure 2).

The highest BNF rates were associated with the lowest concentrations of nitrite and nitrate, that is, in surface waters (Figure 2). BNF rates within the anoxic waters were lower than in the surface waters and were usually below the detection limit. The error bars in Figure 2 represent the s.d. of three biological replicates (that is, water collected in three separate Niskin bottles), and they suggest considerable variability or small-scale patchiness in the rates.
nifH diversity

Three hundred and forty-three DNA and cDNA nifH sequences were obtained from the 10 clone libraries. The majority of the sequences grouped in Cluster I (Table 1) and a large number of sequences grouped in Clusters III and IV (Table 1).

\section{Cluster I}

Samples from all depths from both Stations BB1 and BB2 contained sequences affiliated with Cluster 1 (Figure 3a). A large number of both cDNA and DNA sequences grouped (nt identities between $87 \%$ and 90\%) with Methylocystis rosea, a novel methanotroph that was isolated from Arctic wetland soil. In this alpha Proteobacterial cluster, there were $>50$ sequences from all the three depths at Station BB1, along with sequences from the Arabian Sea ODZ (Jayakumar et al., 2012). However, the only cDNA sequences in this group were obtained from a sample collected from oxic waters at the depth of the chlorophyll maximum and the ODZ depth, both from BB1. Within the alpha Proteobacterial cluster is a subgroup containing sequences from several low oxygen environments, including the Arabian Sea and ETSP ODZs, the South China Sea, mangrove sediments and Great Sippewisset Marsh (MA, USA), but none from the ETNP ODZ samples collected here, nt identities between $92 \%$ and $100 \%$.

Very few sequences grouped in the beta Proteobacterial cluster, but there was no clear separation between the alpha and beta Proteobacterial groups. Six of the nine ETNP sequences in this cluster, plus one sequence obtained from ETSP upwelling region (Fernandez et al., 2015), are related to Sinorhizobium meliloti, an alpha Proteobacterium with nt identities between 68 and $72 \%$. The other three ETNP sequences do not cluster with any cultured bacteria, so we cannot determine whether they belong to the beta or alpha Proteobacterial group.

Thirty-eight DNA and 57 cDNA sequences fell within the gamma Proteobacterial group (Figure 3a). One sequence from the coastal Station BB1 surface sample had high identity with Vibrio diazotrophicus, a gamma Proteobacterium associated with marine cyanobacterial mats (Zehr et al. unpublished). Many of the sequences in this study that clustered in the gamma Proteobacterial group had no close identities to any cultured gamma Proteobacteria but had close identities to sequences derived from the Arabian Sea ODZ and North Pacific gyre. However, several DNA and cDNA sequences from surface samples from both stations and the ODZ depth of BB2 clustered with $P$. stutzeri and $P$. azotifigens $(90-91 \%$ nt identities). Two DNA sequences from the surface waters and one cDNA sequence from BB2 ODZ depth had high identities to sequences associated with copepods and sequences derived from microbial mats on a sandy intertidal beach on a Dutch barrier island. Several DNA and cDNA sequences from BB2 surface sample were closely related to sequences 
a

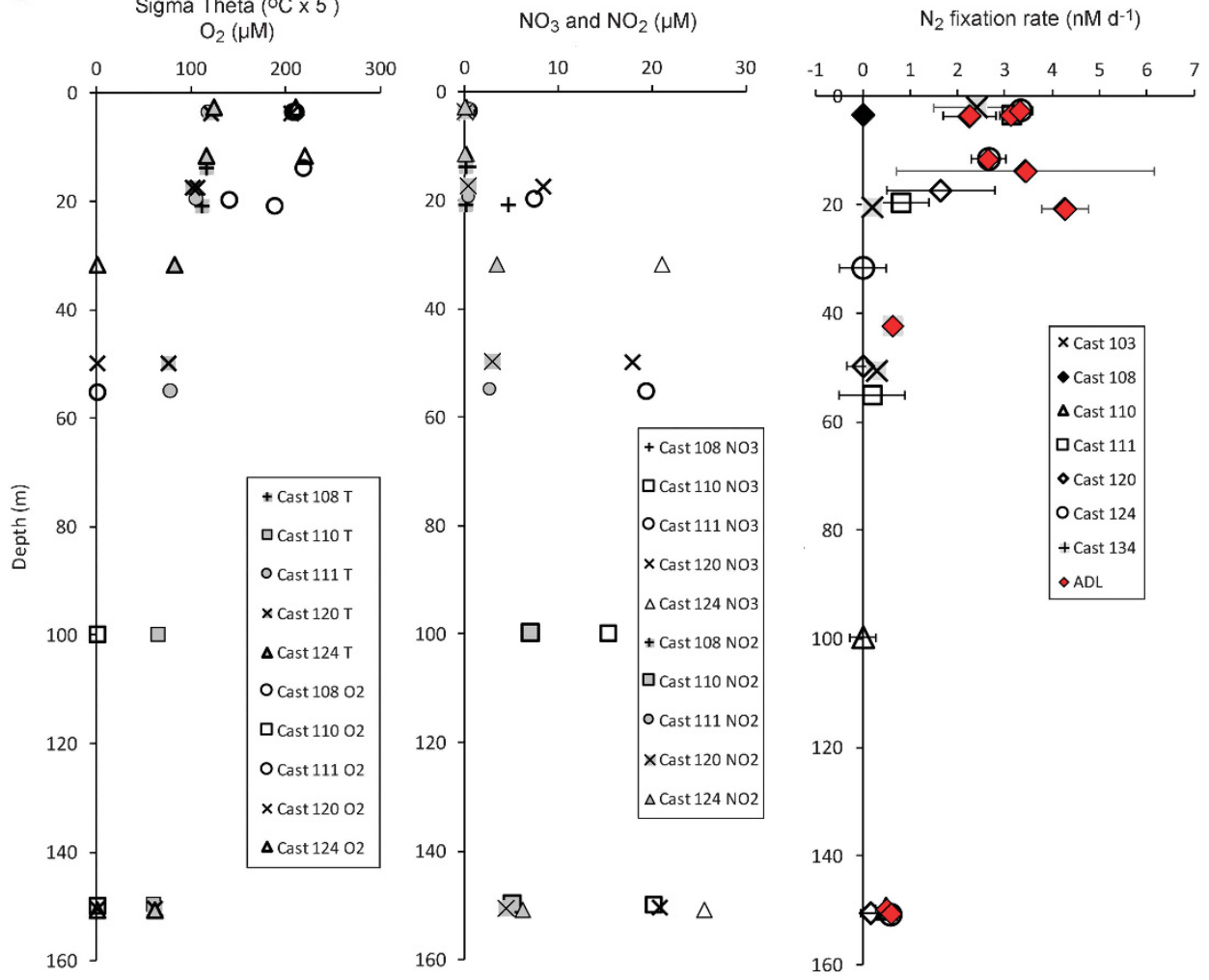

b
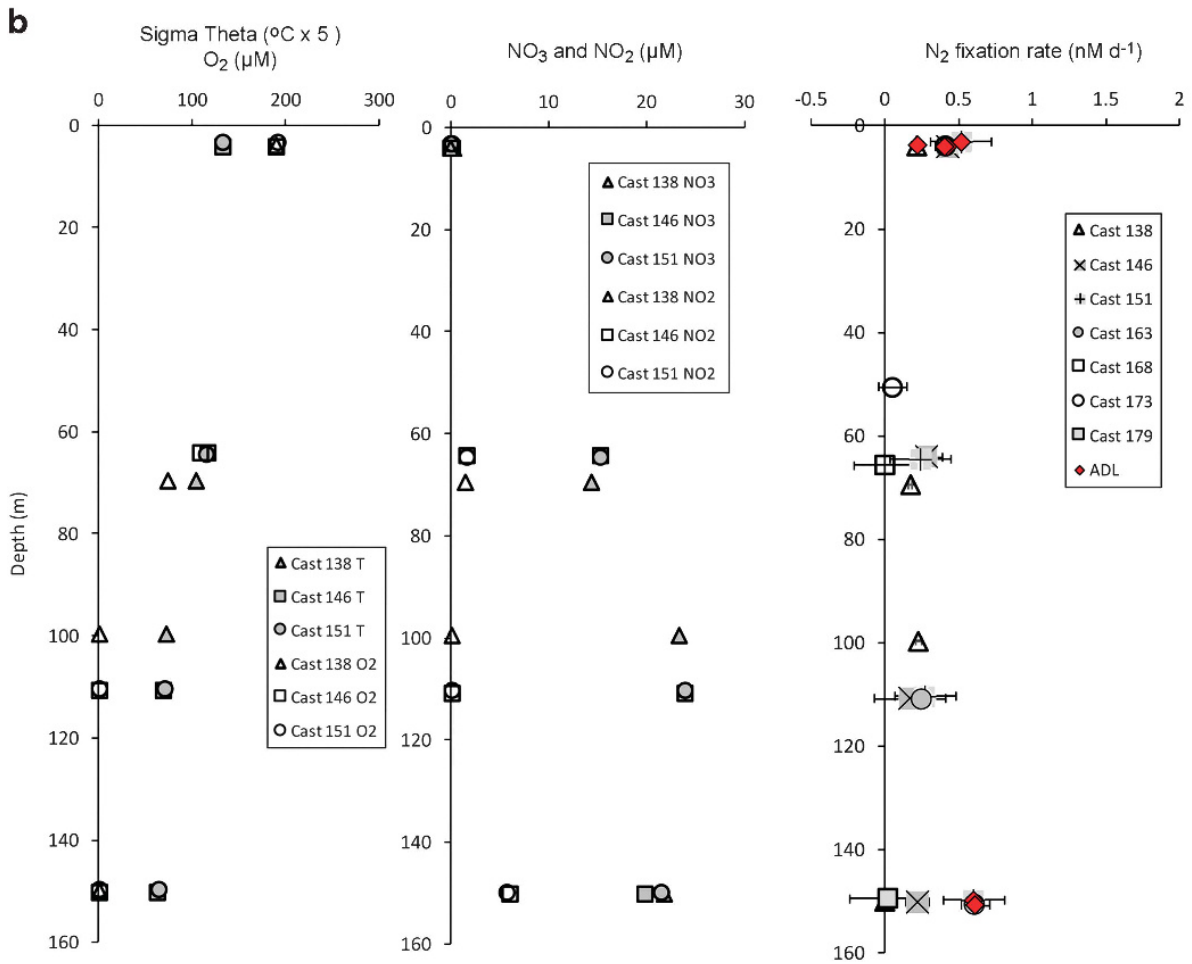

Figure 2 Hydrochemical data and BNF rates at inshore (a) and offshore (b) stations. Red symbols indicate rates that were significantly ADL. All other rates were not significant.

derived from the South Pacific Gyre (Halm et al. (2012); Turk-Kubo et al. (2014) and Arabian Sea Bird et al. (2005). Eight sequences from BB2 surface sample were closely related to nifH sequences from axenic cultures of Marichromatium purpuratum (Braun et al., 1999), obtained from enrichments with planktonic invertebrates. Sequences derived from Arabian Sea were also closely related to this group. 
Table 1 nifH sequence distribution

\begin{tabular}{|c|c|c|c|}
\hline Group & $D N A$ & $c D N A$ & Depths \\
\hline Cluster I & 126 & 86 & $\begin{array}{l}\text { BB1-0M } \\
\text { BB1-18M } \\
\text { BB1-90M } \\
\text { BB2-0M } \\
\text { BB2-150M }\end{array}$ \\
\hline Alphaproteobacteria & 78 & 25 & $\begin{array}{l}\text { BB1-0M } \\
\text { BB1-18M } \\
\text { BB1-90M } \\
\text { BB2-0M } \\
\text { BB2-150M }\end{array}$ \\
\hline Betaproteobacteria & 8 & 1 & $\begin{array}{l}\text { BB1-90M } \\
\text { BB2-0M } \\
\text { BB2-150M }\end{array}$ \\
\hline Gammaproteobacteria & 38 & 57 & $\begin{array}{l}\text { BB1-0M } \\
\text { BB2-0M } \\
\text { BB2-150M }\end{array}$ \\
\hline Deltaproteobacteria & 2 & 0 & $\begin{array}{l}\text { BB1-0M } \\
\text { BB2-0M }\end{array}$ \\
\hline Cyanobacteria & 0 & 3 & BB2-0M \\
\hline Cluster II & 0 & 0 & None \\
\hline Cluster III & 23 & 1 & $\begin{array}{l}\text { BB1-0M } \\
\text { BB1-90M } \\
\text { BB2-0M }\end{array}$ \\
\hline Cluster IV & 33 & 74 & $\begin{array}{l}\text { BB1-90M } \\
\text { BB2-150M }\end{array}$ \\
\hline Total & 182 & 161 & \\
\hline
\end{tabular}

However, no sequences with high identities to Azotobacter vinelandii were detected in this study, although those were found in the Arabian Sea ODZ (Jayakumar et al., 2012).

Three cDNA sequences identical to Trichodesmium erythraeum were found in surface water samples from Station BB2. These had 98\% nt identities to the uncultured Trichodesmium clones reported by Church et al. (2005) that were used to design the most widely used quantitative PCR assay for Trichodesmium. No sequences with high identities to any other cyanobacteria were found. Two DNA sequences from the same sample were very closely related to sequences derived from a number of environments, including Chesapeake Bay water, soil, intertidal microbial mat and other marine environments. A subgroup within this cluster had close identities to sequences from the Arabian Sea ODZ and Geobacter species. On the basis of affinity to Geobacter, we assigned this subgroup to the delta Proteobacteria.

\section{Clusters II, III, and IV}

No sequences from samples collected in the ETNP as part of this study grouped in Cluster II. In Cluster III, two sequences from the coastal Station BB1 at the depth of the SNM had $100 \%$ identity to a sequence obtained from the Montgri Coast of Spain in the Mediterranean Sea (Ribes et al., 2015; Figure 3b).

Another sequence from the SNM at Station BB1 was closely related ( $83 \%$ nt identities) to a sequence derived from water collected near the Great Barrier Reef. This cluster also contained two sequences from the Verrumicrobiae group (Opitutaceae bacterium, isolated from Termite gut, implying the ability to break down cellulose, and Verrucomicrobiae bacterium DG1235). Bacteria in this phylum are usually found in eutrophic environments.

Two cDNA sequences from the ODZ (the SNM) at the coastal Station BB1 were quite distinct from each other but grouped in Cluster IV with Leptolyngbya boryana IAM M-101, an $\mathrm{N}_{2}$-fixing cyanobacterium (Fujita et al., 1991; Figure 3b). However, Cluster IV nifH sequences encode chlorophyllide reductases and are not nitrogen-fixing genes but are found in cyanobacteria. Four sequences from the SNM at both BB1 and BB2 clustered with sequences $(53 \%$ nt identities) from an uncultured soil bacterium (Berthrong et al., 2014), and several cDNA sequences from the SNM samples clustered with Desulfitobacterium hafniense, a spore-forming anaerobic bacterium.

\section{Discussion}

In order to determine the relative magnitude of $\mathrm{N}$ inputs in surface and aphotic waters and with respect to gradients in oxygen concentrations, BNF was measured in vertical profiles in the ETNP above, within and below the ODZ. The highest $\mathrm{N}_{2}$-fixation rates were measured in surface waters but ADL rates were also detected in a few samples collected from ODZ depths.

In order to compare the magnitude of BNF in relation to $\mathrm{N}$ loss processes and to evaluate the significance of BNF in aphotic waters, it is first necessary to obtain accurate estimates of BNF rates. The most widely used method for measuring BNF, the 'bubble' method, can yield underestimates of $\mathrm{N}_{2}$ fixation (Mohr et al., 2010), which can have major implications for balancing the marine $\mathrm{N}$ budget (Großkopf et al., 2012). Großkopf et al. (2012) calculated that the conventional bubble method leads to an underestimation of global $\mathrm{N}_{2}$-fixation rates by about a factor of two. In a direct comparison of the bubble method (in which the tracer is added as a bubble of ${ }^{15} \mathrm{~N}_{2}$ gas) versus the 'dissolution' method (in which the tracer ${ }^{15} \mathrm{~N}_{2}$ is preequilibrated in filtered and degassed sea water and then added to the incubation), the dissolved tracer additions resulted in 2-3.5-fold higher $\mathrm{N}_{2}$-fixation rates than the bubble method (Wilson et al., 2012). The method we used was designed to overcome limitations of both approaches. The main problem with the bubble method is that full isotopic equilibration between the ${ }^{15} \mathrm{~N}_{2}$ tracer and ambient $\mathrm{N}_{2}$ in incubated seawater is assumed right from the beginning of the incubation. In practice, however, the bubble does not equilibrate completely with the aqueous phase $\mathrm{N}_{2}$, even over the course of a 24-h incubation, leading to an overestimate of the isotopic enrichment of the 


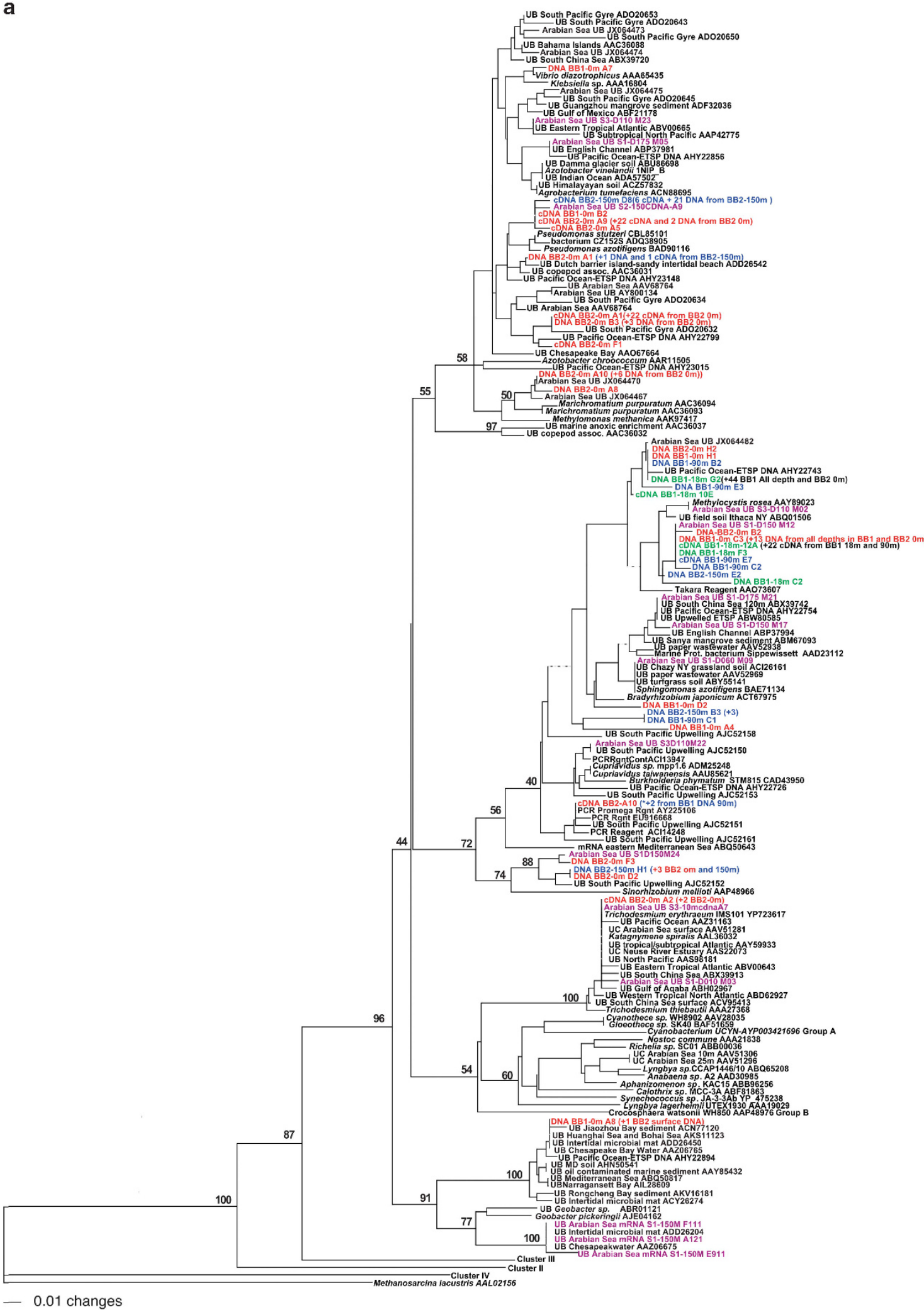

Figure 3 Phylogenetic trees of nifH sequences. DNA and cDNA sequences from the current study are highlighted in color with the clone number at the end and coded for depth: surface samples in red, chlorophyll maximum depth in green and ODZ depths in blue and from the Arabian Sea OMZ region in magenta (Jayakumar et al., 2012). Sequences from other studies are in black, with the NCBI Accession number at the end. UB = uncultured bacterium. (a) nifH phylogeny within nifH Cluster I. (b) nifH phylogeny within Clusters II, III and IV. 


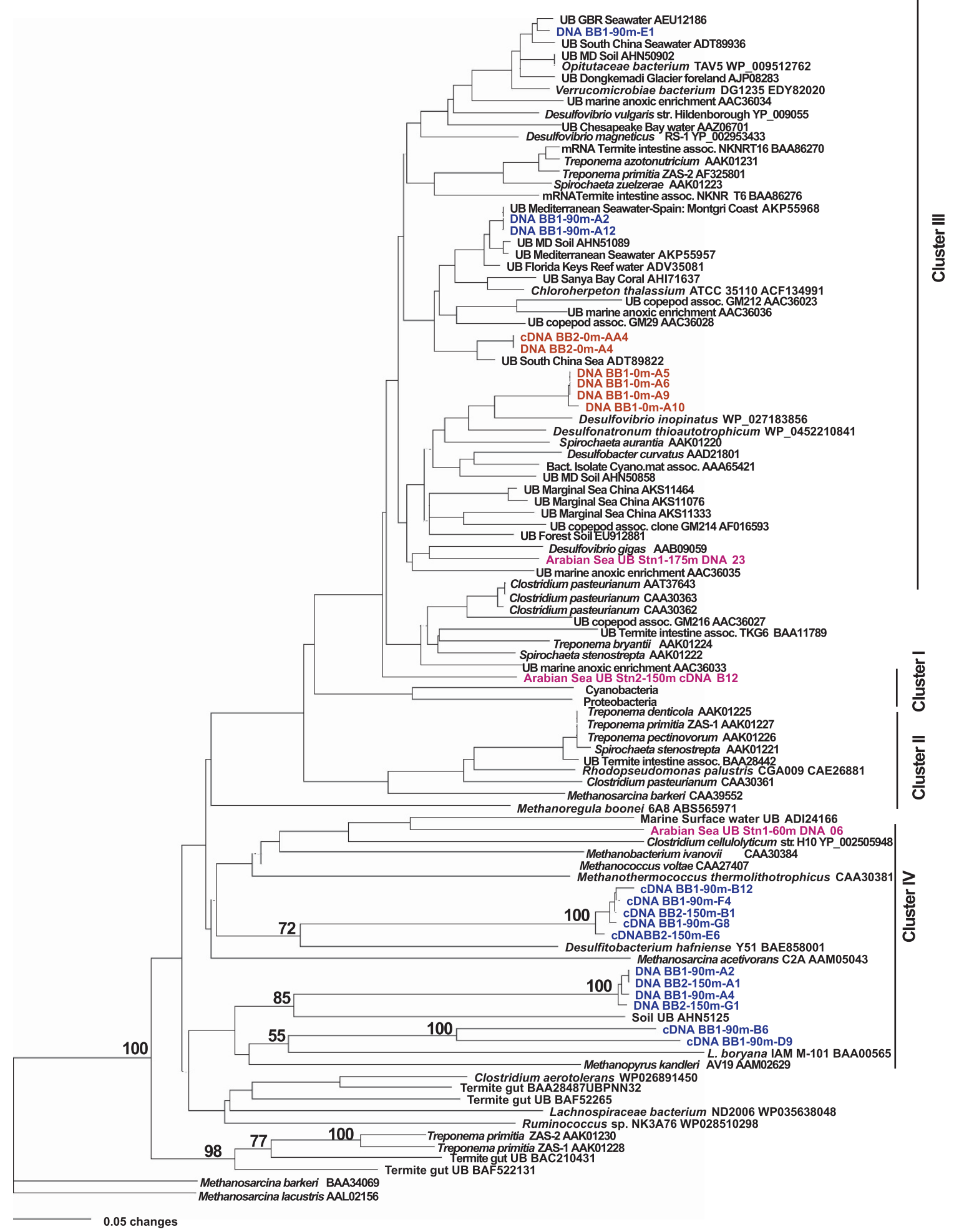

Figure 3 (continued).

dissolved $\mathrm{N}_{2}$ pool and an underestimate of the calculated BNF rate (see Equation 1). The dissolution method requires substantial time and manipulation to filter, degas and preequilibrate site water with
${ }^{15} \mathrm{~N}_{2}$, and it is almost impossible to generate sufficient quantities of enriched water that has the unique physical and chemical properties of each water sample in a reasonable amount of time. 
The preparation of enriched seawater requires degassing, which changes, among other things, the carbonate chemistry and $\mathrm{pH}$ by outgassing of carbon dioxide. Its addition to sample incubation bottles has unknown effects on the microbial community. For ODZ samples, there is the added complication of oxygen contamination.

To avoid the limitations of the bubble method, we adopted a modified bubble method to measure the rates of BNF in the ETNP. Highly enriched tracer was added to incubations as a bubble, but the amount of isotope enrichment over time was directly measured in parallel incubations so that the actual substrate enrichment was known. Avoiding preequilibration steps allowed us to initiate the incubations rapidly upon sample collection and monitoring the actual tracer enrichment allowed us to calculate the ${ }^{15} \mathrm{~N}_{2}$ uptake rates more accurately. In addition, the rigorous determination of detection limit for each individual rate measurement, as applied here, may support more robust conclusions than was possible in some earlier reports.

Contamination of the tracer ${ }^{15} \mathrm{~N}_{2}$ gas has recently been identified as another potential source of artifact in the measurement of $\mathrm{N}_{2}$-fixation rates (Dabundo et al., 2014). We calculated the $\mathrm{N}_{2}$-fixation rate that would have been inferred from the uptake of ${ }^{15} \mathrm{~N}$ contaminants using the finite-differencing model approach of Dabundo et al. (2014), assuming the highest level of contamination found in lots from Cambridge Isotopes $\left(0.052 \mu \mathrm{mol}{ }^{15} \mathrm{NH}_{4}^{+}\right.$per mole ${ }^{15} \mathrm{~N}_{2}$; Dabundo et al., 2014), in conjunction with the measured values of nutrients and particulate nitrogen concentration found in this study (additionally assuming ambient $\delta^{15} \mathrm{~N}-\mathrm{NH}_{4}^{+}=-2 \%$ and a specific growth rate coefficient of $0.3 \mathrm{day}^{-1}$ ). The rates of $\mathrm{N}_{2}$ fixation inferred from the potential uptake of ${ }^{15} \mathrm{~N}$ contaminants ranged from undetectable to $0.019 \mathrm{nmol} \mathrm{N}^{-1} \mathrm{l}^{-1}$ day $^{-1}$, averaging $0.008 \mathrm{nmol} \mathrm{N}^{-1} \mathrm{l}^{-1} \mathrm{day}^{-1}$. This was $\leqslant 7 \%$ of the magnitude of detectable $\mathrm{N}_{2}$-fixation rates measured in this study (average $2 \%$ ), indicating that the ${ }^{15} \mathrm{~N}$ enrichment of particulate nitrogen observed in this study was overwhelming from $\mathrm{N}_{2}$ fixation and not the uptake of ${ }^{15} \mathrm{~N}$ contaminants.

$\mathrm{N}_{2}$-fixation rates have been reported from several recent investigations of $\mathrm{N}$ cycling in OMZs that employed the standard bubble method of tracer addition. In waters offshore of the OMZ in the ETSP, $\mathrm{BNF}$ rates were highest in surface waters (up to $0.9 \mathrm{~nm} \mathrm{day}^{-1}$ ) and rates of up to $0.6 \mathrm{~nm} \mathrm{day}^{-1}$ were detected in low $\mathrm{O}_{2}$ deep water (600 m) (Bonnet et al., 2013; Dekaezemacker et al., 2013; Turk-Kubo et al., 2014). Loscher et al. (2014) reported very high BNF rates $\left(\sim 25 \mathrm{~nm} \mathrm{day}^{-1}\right)$ in surface waters at a eutrophic coastal station in the ETSP and nearly $10 \mathrm{~nm} \mathrm{day}^{-1}$ in the sulfidic bottom water at that station. Similarly, high rates of $\mathrm{N}_{2}$ fixation were observed in surface waters in the coastal North Atlantic Ocean (Mulholland et al., 2012). However, not only are these rates likely underestimates based on the methodological considerations outlined above but might also be usefully re-evaluated with stricter detection limits.

The BNF rates reported here are among the first from the ETNP ODZ so it is useful to compare them with those from the ETSP and elsewhere. White et al. (2013) reported low integrated $\mathrm{N}$-fixation rates (based on the bubble method) in the surface layer at two stations in the region of the current study, but it is difficult to make direct comparisons because depth profiles were not provided and the ODZ depths were not sampled. Surface waters from the coastal Station BB1 (total depth $2330 \mathrm{~m}$ ) were less eutrophic than the sulfidic coastal station in the ETSP occupied by Loescher et al. (2014). The open ocean Station BB2 sampled in this study was within the ETNP ODZ. In contrast, Bonnet et al. (2013) sampled the outer edge of the ODZ in the ETSP. Surface BNF rates measured at Station BB1 were higher than those measured further offshore in the ETSP (Bonnet et al., 2013) but lower than those observed at the coastal ETSP site (Loescher et al., 2014). BNF rates measured at Station BB2 were the same order of magnitude as those from the offshore ETSP station (Bonnet et al., 2013) and comparable to rates measured in samples collected at $40 \mathrm{~m}$ at a nearshore station in the ETSP (Loescher et al., 2014) and hypoxic waters of the Southern California Bight (0.07-0.25 nм day ${ }^{-1}$; Hamersley et al., 2011). Although the rates reported here for the ETNP may be more accurate than those obtained with the standard bubble method, they are not substantially different in magnitude. The rates reported here are within the range of those reported previously for ODZs and lower than those reported for surface waters. BNF rates in the coastal surface waters were comparable to rates measured in coastal surface waters in the ETSP and elsewhere (Mulholland et al., 2012) and so represent a previously unquantified source of fixed $\mathrm{N}$.

Denitrification and anammox rates have been reported previously for samples collected at the same stations during this cruise (Babbin et al., 2014). Total $\mathrm{N}$ loss rates were highest near the top of the ODZ and decreased with increasing depth in accordance with the Martin curve (Martin et al., 1987). Maximum $\mathrm{N}$ loss rates of nearly $30 \mathrm{~nm} \mathrm{~N}$ day $^{-1}$ were observed at the coastal Station BB1 at $60 \mathrm{~m}$ and rates of $\sim 10 \mathrm{nM} \mathrm{N}$ day $^{-1}$ occurred near $100 \mathrm{~m}$ at both Stations BB1 and BB2. In contrast, maximum BNF rates occurred in the euphotic zone in the upper $20 \mathrm{~m}$, much shallower than the depth of the maximum in $\mathrm{N}$ loss rates. At depths in the core of the ODZ $(>60 \mathrm{~m}$ at BB1 and $>100 \mathrm{~m}$ at BB2), volumetric $\mathrm{N}$ loss rates exceeded $\mathrm{BNF}$ rates by a factor of $\sim 20$.

Because reliable oxygen concentration measurements are sparse, we took the approach of Babbin et al. (2015), who used a corrected World Ocean Atlas dissolved oxygen database and set the dissolved oxygen definition for ODZ waters at $2.5 \mu \mathrm{M}$. By this definition, the volume of the anoxic water in 
the ETNP was estimated to be $1.2 \pm 0.5 \times 10^{15} \mathrm{~m}^{3}$. The average of ADL rates in the ODZ (0.79 $\left.\mathrm{nm} \mathrm{day}^{-1}\right)$ was multiplied by this volume of water to yield an estimate of $0.1 \mathrm{Tg} \mathrm{N}$ year $^{-1}$ for the total BNF rate in the anoxic waters of the ETNP. However, this value should be considered an upper limit because it does not include zero values for BNF observed in most incubations in the ODZ. For perspective, the global water column BNF rate is estimated to be $140 \mathrm{Tg} \mathrm{N}_{\text {year }}{ }^{-1}$ (Deutsch et al., 2007). The measured anoxic BNF rates suggest that $\mathrm{N}_{2}$ fixation in the ODZ of the ETNP is not a significant contribution to the global $\mathrm{N}$ budget. The global water column denitrification rate is estimated at $70 \mathrm{Tg} \mathrm{N}$ year $^{-1}$ (Devries et al., 2012). If the ETNP region accounts for $30 \%$ of the global water column $\mathrm{N}$ loss (21 $\mathrm{Tg} \mathrm{N}_{\mathrm{Near}}{ }^{-1}$ ), our estimated maximum anoxic BNF rate for the ETNP of $0.1 \mathrm{Tg} \mathrm{N}$ year $^{-1}$ could not significantly offset that loss.

The main conclusion from the present study is that, even with improved incubation methods, sensitive mass spectrometry, careful replication and robust statistical analysis, $\mathrm{BNF}$ rates are low in the ETNP in both surface and anoxic waters. The data set we report here is small and highly variable and so a more comprehensive examination of $\mathrm{N}_{2}$ fixation in oxygen-deficient waters is necessary before concluding that anoxic BNF is not a significant component of the $\mathrm{N}$ cycle.

As in the current study, most of the nifH sequences from the ETSP aphotic/anoxic waters were associated with Cluster I and affiliated with various branches of the Proteobacteria (Bonnet et al., 2013; Loescher et al., 2014; Turk-Kubo et al., 2014). However, unlike the Arabian Sea, a large number of sequences from the ETNP ODZ also grouped in Clusters III and IV.

Similar to the ETNP, diverse gamma Proteobacteria were found in the ETSP (Turk-Kubo et al., 2014), but quantitative PCR assays indicated that their abundance was too low to account for the measured BNF rates there. These authors argued that, despite the diversity of novel diazotrophs in subsurface waters, the agents responsible for the measured BNF remain unidentified and possibly so divergent as to have avoided detection so far.

Despite the fact that the highest BNF rates were found in surface waters, we retrieved very few nifH sequences affiliated with known cyanobacterial $\mathrm{N}_{2}$ fixers. Only three Trichodesmium sequences were found in the offshore surface sample even though this ubiquitous group is found almost everywhere in the subtropical surface ocean. Similarly, Turk-Kubo et al. (2014) detected only three cyanobacterial phylotypes in the ETSP, including a novel Trichodesmium type, which accounted for only $4 \%$ of the sequences in their clone libraries and could not be quantified by quantitative PCR. In the present study, it was not possible to distinguish heterotrophic from cyanobacterial $\mathrm{N}_{2}$ fixation in surface waters. Although cyanobacterial diazotrophs are generally the targets for quantitative PCR in surface waters, heterotrophic diazotrophs are also retrieved in clone libraries of surface water samples and may contribute to BNF in the euphotic zone (Mulholland et al., 2012). Amplification and/or cloning bias depending on the PCR primers cannot be discounted as part of the reason for low detection of cyanobacterial nifH sequences, but low rates and low cyanobacterial abundance are consistent with a relatively minor role for of $\mathrm{N}$ fixation in this region. In the region of the stations sampled here, White et al. (2013) detected low numbers of Trichodesmium filaments and low abundance of the cyanobacterial-symbiontbearing diatom, Richelia. White et al. (2013) also concluded that diazotrophy was a relatively minor contribution to the $\mathrm{N}$ budget and to sinking particulate flux.

The highest $\mathrm{BNF}$ rates in the ETNP were detected in surface waters where fixed $\mathrm{N}$ concentrations were very low. It does not appear, however, that fixed $\mathrm{N}$ availability is the major control variable on BNF, as has been observed in the coastal Atlantic Ocean (Mulholland et al., 2012). In the present study, we detected active BNF in dissolved inorganic nitrogenreplete $(>20 \mu \mathrm{M})$ aphotic waters below the nitracline (Figure 2). The main diazotrophs detected in this region, in both surface and deep waters, both oxic and anoxic conditions, were Proteobacteria, presumably mainly heterotrophic. Why $\mathrm{N}$ fixation would be advantageous over assimilation of dissolved inorganic nitrogen or dissolved organic nitrogen is unknown.

Similarly, while low oxygen concentrations are thought to be favorable for BNF, we measured the highest BNF rates in oxic surface waters. Our results are consistent with other recent studies in suggesting that the habitat for diazotrophy includes dark deep water replete with fixed $\mathrm{N}$ (Rahav et al., 2013; Loescher et al., 2014; Turk-Kubo et al., 2014), where $\mathrm{BNF}$ is accomplished by diverse heterotrophic diazotrophic assemblages.

\section{Conclusions}

Low rates of BNF were detected in both surface and anoxic waters in the ETNP ODZ region. Combined findings of BNF in surface waters and anoxic deep waters of the ETNP, in the ETSP and elsewhere in anoxic waters may warrant a re-evaluation of the global $\mathrm{N}$ budget but are unlikely to change it very much. In the ETNP, BNF was apparently conducted by novel bacterial groups in the presence of high concentrations of fixed $\mathrm{N}$, thus emphasizing the need to re-evaluate our understanding of the regulation of $\mathrm{BNF}$ in the ocean.

\section{Conflict of Interest}

The authors declare no conflict of interest. 


\section{Acknowledgements}

We are grateful for the help provided by the captain and crew of the $R / V$ Thomas $G$. Thompson and chief scientist $\mathrm{AH}$ Devol for assistance in sampling and A Morello for help with nutrient measurements. We also thank J Granger for providing us with the finite-differencing model used to calculate $15 \mathrm{~N}$-contamination-sourced ' $\mathrm{N}_{2}$-fixation' rates. This work was funded by NSF grant no. OCE-1029951 to BBW and AJ and NSF grant no. OCE-1356043 to MRM, AJ and BXC. This is NOAA-PMEL contribution no. 4566. This publication is partially funded by the Joint Institute for the Study of the Atmosphere and Ocean (JISAO) under NOAA Cooperative Agreement NA10OAR4320148 (2010-2015) and NA15OAR4320063 (2015-2020), contribution no. 2016-01-46.

\section{References}

Babbin AR, Bianchi, Jayakumar A, Ward BB. (2015). Rapid nitrous oxide cycling in the suboxic ocean. Science 348: 1127-1129.

Babbin AR, Keil RG, Devol AH, Ward BB. (2014). Organic matter stoichiometry, flux, and oxygen control nitrogen loss in the ocean. Science 344: 406-408.

Berthrong ST, Yeager CM, Gallegos-Graves L, Steven B, Eichorst SA, Jackson RB et al. (2014). Nitrogen fertilization has a stronger effect on soil nitrogenfixing bacterial communities than elevated atmospheric $\mathrm{CO}_{2}$. Appl Environ Microb 80: 3103-3112.

Bird C, Martinez J, O’Donnell A, Wyman M. (2005). Spatial distribution and transcriptional activity of an uncultured clade of planktonic diazotrophic gammaproteobacteria in the Arabian Sea. Appl Environ Microb 71: 2079-2085.

Bonnet S, Dekaezemacker J, Turk-Kubo KA, Moutin T, Hamersley RM, Grosso O et al. (2013). Aphotic N-2 fixation in the Eastern Tropical South Pacific Ocean. PLos One 8: e81265.

Braun ST, Proctor LM, Zani S, Mellon MT, Zehr JP. (1999). Molecular evidence for zooplankton-associated nitrogen-fixing anaerobes based on amplification of the nifH gene. FEMS Microbiol Ecol 28: 273-279.

Church MJ, Jenkins BD, Karl DM, Zehr JP. (2005). Vertical distributions of nitrogen-fixing phylotypes at stn ALOHA in the oligotrophic North Pacific Ocean. Microb Ecol 38: 3-14.

Dabundo R, Lehmann MF, Treibergs L, Tobias CR, Altabet MA, Moisander $\mathrm{PH}$ et al. (2014). The contamination of commercial N-15(2) gas stocks with $\mathrm{N}$-15-labeled nitrate and ammonium and consequences for nitrogen fixation measurements. PLos One 9: e110335.

Dekaezemacker J, Bonnet S, Grosso O, Moutin T, Bressac M, Capone DG. (2013). Evidence of active dinitrogen fixation in surface waters of the eastern tropical South Pacific during El Nino and La Nina events and evaluation of its potential nutrient controls. Global Biogeochem Cycles 27: 768-779.

Deutsch C, Sarmiento JL, Sigman DM, Gruber N, Dunne JP. (2007). Spatial coupling of nitrogen inputs and losses in the ocean. Nature 445: 163-167.

Devol AH. (2008). Denitrification, including Anammox. In: Capone DG, Bronk DA, Mulholland MR, Carpenter EJ (eds). Nitrogen in the Marine Environment. 2nd edn. Elsevier: Amsterdam, The Netherlands, pp 263-301.

Devries T, Deutsch C, Primeau F, Chang B, Devol A. (2012). Global rates of water-column denitrification derived from nitrogen gas measurements. Nat Geosci 5: 547-550.

Fernandez C, Gonzalez ML, Muñoz C, Molina V, Farias L. (2015). Temporal and spatial variability of biological nitrogen fixation off the upwelling system of central Chile (35-38.5으. J Geophys Res Oceans 120: 3330-3349.

Fernandez C, Farias L, Ulloa O. (2011). Nitrogen fixation in denitrified marine waters. PLos One 6: e20539.

Fujita Y, Takahashi Y, Shonai F, Ogura Y, Matsubara H. (1991). Cloning, nucleotide-sequences and differential expression of the nifH and nifH-like (frxC) genes from the filamentous nitrogen -fixing cyanobacterium Plectonema boryanum. Plant Cell Physiol 32: 1093-1106.

Großkopf T, Laroche J. (2012). Direct and indirect costs of dinitrogen fixation in Crocosphaera watsonii WH8501 and possible implications for the nitrogen cycle. Front Microbiol 3: 236.

Großkopf T, Mohr W, Baustian T, Schunck H, Gill D, Kuypers MMM et al. (2012). Doubling of marine dinitrogen-fixation rates based on direct measurements. Nature 488: 361-364.

Hamersley MR, Turk KA, Leinweber A, Gruber N, Zehr JP, Gunderson T et al. (2011). Nitrogen fixation within the water column associated with two hypoxic basins in the Southern California Bight. Aquat Microb Ecol 63: 193-+.

Halm H, Lam P, Ferdelman TG, Lavik G, Dittmar T, LaRoche J et al. (2012). Heterotrophic organisms dominate nitrogen fixation in the South Pacific Gyre. ISME J 6: 1238-1249.

Jayakumar A, Al-Rshaidat MMD, Ward BB, Mulholland MR. (2012). Diversity, distribution, and expression of diazotroph nifH genes in oxygendeficient waters of the Arabian Sea. FEMS Microbiol Ecol 82: 597-606.

Loescher CR, Grosskopf T, Desai FD, Gill D, Schunck H, Croot PL et al. (2014). Facets of diazotrophy in the oxygen minimum zone waters off Peru. ISME J 8: $2180-2192$

Martin JH, Knauer GA, Karl DM, Broenkow WW. (1987). Vertex-carbon cycling in the Northeast Pacific. Deep Sea Res Part A Oceanogr Res Pap 34: 267-285.

Mcilvin MR, Casciotti KL. (2010). Fully automated system for stable isotopic analyses of dissolved nitrous oxide at natural abundance levels. Limnol Oceanogr Methods 8: $54-66$.

Mohr W, Grosskopf T, Wallace DWR, Laroche J. (2010). Methodological underestimation of oceanic nitrogen fixation rates. PLos One 5: e12583.

Montoya JP, Voss M, Kaehler P, Capone DG. (1996). A simple, high-precision, high-sensitivity tracer assay for N2 fixation. Appl Environ Microb 62: 986-993.

Mulholland MR, Bernhardt PW, Heil CA, Bronk DA, O'Neil JM. (2006). Nitrogen fixation and release of fixed nitrogen by Trichodesmium spp. in the Gulf of Mexico. Limnol Oceanogr 51: 1762-1776.

Mulholland MR, Bernhardt PW, Blanco-Garcia JL, Mannino A, Hyde K, Mondragon E et al. (2012). Rates of dinitrogen fixation and the abundance of diazotrophs in North American coastal waters between 
Cape Hatteras and Georges Bank. Limnol Oceanogr 57: 1067-1083.

Mulholland MR, Capone DG. (2009). Dinitrogen fixation in the Indian Ocean. In: Wiggert JD, Hood RR, Naqvi SWA, Brink KH, Smith SL (eds). Indian Ocean Biogeochemical Processes and Ecological Variability. American Geophysical Union: Washington, DC, USA, pp 167-186.

Peng X, Fuchsman CA, Jayakumar A, Oleyni S, Martens-Habbena W, Devol AH et al. (2015). Ammonia and nitrite oxidation in the Eastern Tropical North Pacific. Glob Biogeochem Cycles 29: 2034-2049.

Rahav E, Bar-Zeev E, Ohayon S, Elifantz H, Belkin N, Herut B et al. (2013). Dinitrogen fixation in aphotic oxygenated marine environments. Front Microbiol 4: 00227.

Ribes M, Dziallas C, Coma R, Riemann L. (2015). Microbial diversity and putative diazotrophy in high- and lowmicrobial-abundance mediterranean sponges. Appl Environ Microb 81: 5683-5693.

Santoro AE, Sakamoto CM, Smith JM, Plant JN, Gehman AL, Worden AZ et al. (2013). Measurements of nitrite production in and around the primary nitrite maximum in the central California Current. Biogeosciences 10: 7395-7410.

Thamdrup B, Dalsgaard T. (2002). Production of $\mathrm{N}_{2}$ through anaerobic ammonium oxidation coupled to nitrate reduction in marine sediments. Appl Environ Microb 68: 1312-1318.

Thompson JD, Gibson TJ, Plewniak F, Jeanmougin F, Higgins DG. (1997). The CLUSTAL_X windows interface: flexible strategies for multiple sequence alignment aided by quality analysis tools. Nucleic Acids Res 25: 4876-4882.

Tiano L, Garcia-Robledo E, Dalsgaard T, Devol AH, Ward BB, Ulloa O et al. (2014). Oxygen distribution and aerobic respiration in the north and south eastern tropical Pacific oxygen minimum zones. Deep Sea Res Part I Oceanogr Res Pap 94: 173-183.

Turk-Kubo KA, Karamchandani M, Capone DG, Zehr JP. (2014). The paradox of marine heterotrophic nitrogen fixation: abundances of heterotrophic diazotrophs do not account for nitrogen fixation rates in the Eastern Tropical South Pacific. Environ Microbiol 16: 3095-3114.

White AE, Foster RA, Benitez-Nelson CR, Masque P, Verdeny E, Popp BN et al. (2013). Nitrogen fixation in the Gulf of California and the Eastern Tropical North Pacific. Prog Oceanogr 109: 1-7.

Wilson ST, Boettjer D, Church MJ, Karl DM. (2012). Comparative assessment of nitrogen fixation methodologies, conducted in the Oligotrophic North Pacific Ocean. Appl Environ Microb 78: 6516-6523.

Zani S, Mellon MT, Collier JL, Zehr JP. (2000). Expression of nifH genes in natural microbial assemblages in Lake George, New York, detected by reverse transcriptase PCR. Appl Environ Microb 66: 3119-3124.

Zehr JP, Crumbliss LL, Church MJ, Omoregie EO, Jenkins BD. (2003). Nitrogenase genes in PCR and RT-PCR reagents: implications for studies of diversity of functional genes. Biotechniques 35: 996-1002.

Zehr JP, McReynolds LA. (1989). Use of degenerate oligonucleotides for amplification of the nifH gene from the marine cyanobacterium Trichodesmium theiebautii. Appl Environ Microb 55: 2522-2526.

Zehr JP, Mellon MT, Zani S. (1998). New nitrogen-fixing microorganisms detected in oligotrophic oceans by amplification of nitrogenase (nifH) genes. Appl Environ Microb 6: 3444-3450.

Zehr JP, Montoya JP, Jenkins BD, Hewson I, Mondragon E, Short CM et al. (2007). Experiments linking nitrogenase gene expression to nitrogen fixation in the North Pacific subtropical gyre. Limnol Oceanogr 52: 169-183.

Supplementary Information accompanies this paper on The ISME Journal website (http://www.nature.com/ismej) 